\title{
Article \\ Electrical Capacitance versus Minirhizotron Technique: A Study of Root Dynamics in Wheat-Pea Intercrops
}

\author{
Imre Cseresnyés ${ }^{1}\left(\mathbb{D}\right.$, Bettina Kelemen ${ }^{1, *}$, Tünde Takács ${ }^{1, *}$, Anna Füzy ${ }^{1}$, Ramóna Kovács ${ }^{1}$, Mária Megyeri ${ }^{2}$, \\ István Parádi ${ }^{1,3}$ and Péter Mikó ${ }^{2} \mathbb{D}$ \\ 1 Centre for Agricultural Research, Institute for Soil Sciences, ELKH, Herman Ottó út 15, \\ H-1022 Budapest, Hungary; cseresnyes.imre@atk.hu (I.C.); fuzy.anna@atk.hu (A.F.); \\ kovacsrami@gmail.com (R.K.); istvan.paradi@atk.hu (I.P.) \\ 2 Centre for Agricultural Research, Agricultural Institute, ELKH, Brunszvik u. 2, \\ H-2462 Martonvásár, Hungary; megyeri.maria@atk.hu (M.M.); miko.peter@atk.hu (P.M.) \\ 3 Department Plant Physiology and Molecular Plant Biology, Eötvös Loránd University, Pázmány Péter Stny. \\ 1A, H-1117 Budapest, Hungary \\ * Correspondence: kelemen.bettina@atk.hu (B.K.); takacs.tunde@atk.hu (T.T.)
}

check for updates

Citation: Cseresnyés, I.; Kelemen, B.; Takács, T.; Füzy, A.; Kovács, R.; Megyeri, M.; Parádi, I.; Mikó, P. Electrical Capacitance versus Minirhizotron Technique: A Study of Root Dynamics in Wheat-Pea Intercrops. Plants 2021, 10, 1991. https://doi.org/10.3390/ plants10101991

Academic Editor: Rui Manuel Almeida Machado

Received: 1 September 2021

Accepted: 22 September 2021

Published: 23 September 2021

Publisher's Note: MDPI stays neutral with regard to jurisdictional claims in published maps and institutional affiliations.

Copyright: (c) 2021 by the authors. Licensee MDPI, Basel, Switzerland. This article is an open access article distributed under the terms and conditions of the Creative Commons Attribution (CC BY) license (https:// creativecommons.org/licenses/by/ $4.0 /)$.

\begin{abstract}
This study evaluated the concurrent application and the results of the root electrical capacitance $\left(C_{R}\right)$ and minirhizotron $(M R)$ methods in the same plant populations. The container experiment involved three winter wheat cultivars, grown as sole crops or intercropped with winter pea under well-watered or drought-stressed conditions. The wheat root activity (characterized by $C_{R}$ ) and the MR-based root length (RL) and root surface area (RSA) were monitored during the vegetation period, the flag leaf chlorophyll content was measured at flowering, and the wheat shoot dry mass (SDM) and grain yield (GY) were determined at maturity. $C_{R}, R L$ and RSA exhibited similar seasonal patterns with peaks around the flowering. The presence of pea reduced the maximum $C_{R}, R L$ and RSA. Drought significantly decreased $C_{R}$, but increased the MR-based root size. Both intercropping and drought reduced wheat chlorophyll content, SDM and GY. The relative decrease caused by pea or drought in the maximum $C_{R}$ was proportional to the rate of change in SDM or GY. Significant linear correlations $\left(R^{2}: 0.77-0.97\right)$ were found between $C_{R}$ and $R S A$, with significantly smaller specific root capacitance (per unit RSA) for the drought-stress treatments. $C_{R}$ measurements tend to predict root function and the accompanying effect on above-ground production and grain yield. The parallel application of the two in situ methods improves the evaluation of root dynamics and plant responses.
\end{abstract}

Keywords: cereal-legume intercrops; drought stress; grain yield; in situ root methods; root growth

\section{Introduction}

Owing to methodological difficulties in assessing the growth and activity of intact root systems in the soil [1,2], the application and development of indirect, non-destructive techniques, including electrical methods, have received increasing attention in recent years $[3,4]$.

The electrical capacitance of the root-soil system $\left(C_{R}\right)$, measured using a low-frequency alternating current $(1 \mathrm{kHz} A C)$ between one electrode fixed to the plant stem base and another inserted into the surrounding soil, was reported to correlate with the root system size (RSS) [5]. The first, generally accepted conceptual model, hypothesizes that roots are equivalent to leaky cylindrical capacitors, in which the electrically conductive root sap is separated from the conductive soil solution by polarizable membrane dielectrics [6]. Membranes store electric charges proportional to their surface area, modifying the phase and amplitude of the AC signal.

Nevertheless, some studies revealed the inconsistencies with Dalton's proposals, and questioned the feasibility of the $C_{R}$ method [7]. Dietrich et al. [8,9] suggested a revised model, and explored that $C_{R}$ was dominated by the stem base between the plant electrode 
and the substrate surface (with a negligible contribution of the roots), and was correlated with a stem cross-sectional area. According to their explanation, the $C_{R}-R S S$ correlations are merely due to the allometric relationship between root and shoot traits. Another recent study also suggested that current leakage chiefly occurred in the root neck and proximal roots and much less in the distal segments [10]. In contrast, progressive root cutting and root immersion experiments in hydroponically grown plants supported that $C_{R}$ is highly influenced by the roots located in the media [11]. There is a consensus that the current pathway inside the plant organs is influenced by tissue properties, e.g., suberization $[4,6,12,13]$. Therefore, one advantage of the capacitance method is that $C_{R}$ is a reflection of root size and physiological status, i.e., water content, membrane integrity and permeability, and endodermal maturation, driven by ontogenic changes and environmental (stress) factors [13]. Due to the allometry between the proximal root regions that mostly contribute to current flow and the distal fine roots responsible for solute absorption [8-10], $\mathrm{C}_{\mathrm{R}}$ is related to the water uptake activity of the root system (referred to as "root activity") as a whole $[6,14,15]$.

The rapid $C_{R}$ method is appropriate for monitoring the same plant over time, and for screening large plant populations [16]. As the neighboring plants (with intermingling roots) are not connected electrically, $C_{R}$ provides plant-scale information [13]. An evident drawback to using the technique is the complete lack of root visualization. It is difficult to quantify root traits from capacitance data, which are more suitable for the relative comparison of RSS for the same species, grown in the same substrate and measured under the same conditions [16]. Although $C_{R}$ is strongly affected by the soil water content (SWC), this can be taken into account with species-specific functions [15]. The soil dielectric response tends to reduce the efficiency of the method, particularly in the case of complex soils abounding in surface-charged colloidal particles [3]. Nevertheless, despite the uncertainties about the underlying biophysical mechanisms, the method has proven useful in several studies to evaluate RSS in herbaceous native and crop species and in tree saplings grown in pots [14,17-19] or in the field [13,15,16,20].

The minirhizotron (MR), a more widely used non-destructive visualization technique, allows the dynamic study of root traits at particular locations in the soil profile, including root architecture, branching, depth distribution, length density, production, longevity, mortality, turnover and decomposition [2,21]. However, MR represents only part of the root system, with limited resolution for the fine roots that are responsible for water uptake [22]. The main biases are attributed to the artificial MR tube surface and the poor soil-tube wall contact (including soil gaps), which may result in modified temperature conditions, altered water flow and decreased soil penetration resistance, potentially changing the observed root density and traits $[7,23]$. The critical points in the MR technique are the assessment of root physiological status (activity) by visual evaluation (e.g., color, shrinking, contour smoothing, blotting), and the differentiation between the roots of individual plants [21]. The available data are often limited due to the time-consuming image analysis, and to the lack of automatic image processing methods that give satisfactory results for MR pictures $[2,24]$.

We surmised that the use of the entirely different $C_{R}$ and MR methods in the same root study would be beneficial. In the framework of an EU H2020 project, the aim was to use the two techniques concurrently (which has not previously been reported) in intercropping systems, which are increasingly important in sustainable agriculture $[25,26]$. The more efficient resource utilization in species mixtures compared to sole crops may result in benefits such as higher yield equivalent ratios and yield stability, improved grain quality, enhanced lodging resistance, improved soil conservation and better control of pests and weeds [27,28]. Cereal-legume, including wheat-pea mixtures, are the dominant intercrops in organic farming in Europe [26,29]. Symbiotic $\mathrm{N}_{2}$ fixation in pea more or less satisfies the high $\mathrm{N}$ demand of the cereal $[25,30]$. The complementary resource use and, therefore, growth and yield components, highly depend on the root dynamics, and the root architectural modifications of the mixed species $[1,31]$. The wheat root response to intercropping under 
altered conditions is often highly variable and is hardly predictable [32]. Therefore, in situ root investigation methods were deemed appropriate to track root development over time in mixed crop culture, and to evaluate the responsiveness of the selected wheat cultivars to intercropping under different irrigation conditions. Winter wheat and pea mixtures, grown in containers in the greenhouse, were used for the present methodological study. Although this controlled environment was likely not representative of field conditions, it allowed us to standardize experimental parameters, to adjust contrasting soil moisture regimes, and to eliminate weather anomalies.

In this study, $C_{R}$ and MR measurements were performed in the same intercrop system, aiming specifically (i) to analyze and compare the results provided by the methods during monitoring the response of root dynamics of various wheat genotypes to intercropping and drought, and (ii) to evaluate the potential benefits of the simultaneous application of the two approaches.

\section{Results}

\subsection{Root Electrical Capacitance}

The apparent root capacitance $\left(\mathrm{C}_{\mathrm{R}}{ }^{*}\right)$ obtained for the well-watered sole wheat crops increased rapidly over time until DAP 65 for cultivars 'Mv Nádor' (9.2 nF) and 'Mv Kolompos' (13.0 nF), and until DAP 77 for YQCCP (11.3 nF; Figure 1a). The peak of $C_{R}{ }^{*}$ coincided with the early or full flowering stage $(\mathrm{BBCH} 61-65)$ in each case. The intercropped wheats showed similar phenology and temporal $C_{R}{ }^{*}$ patterns. The presence of pea caused a decrease in wheat root capacitance (with maxima of 7.6, 11.2 and $10.7 \mathrm{nF}$ for 'Mv Nádor', 'Mv Kolompos' and YQCCP, respectively); in general, this effect was significant from DAP 31 (stem elongation) to DAP 88 (milky or early dough) (Table S1).

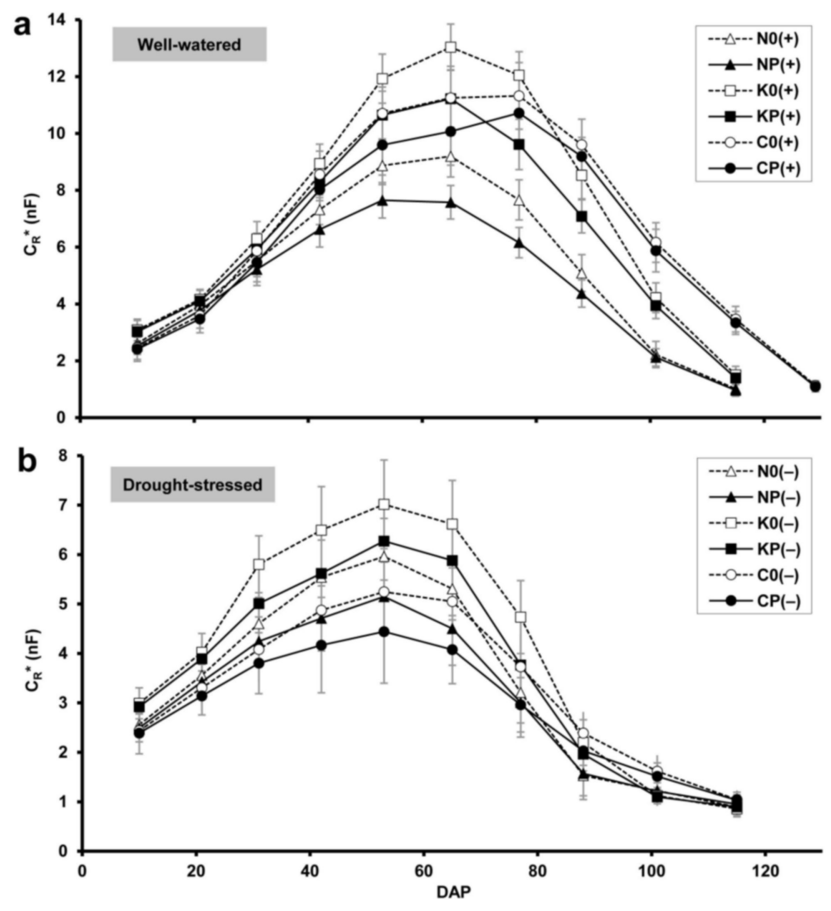

Figure 1. Changes in the apparent root electrical capacitance $\left(C_{R}^{*}\right.$; in nanofarads, $\left.n F\right)$ of wheat with plant age (DAP: days after planting) under (a) well-watered and (b) drought-stressed conditions. Bars show standard deviations $(n=30)$. Treatment codes: N: wheat cv. Mv Nádor; K: cv. Mv Kolompos; C: YQCCP population; 0: wheat sole crop; P: wheat-pea intercrop; (+): well-watered; (-): drought-stressed.

Under drought, both sole and intercropped wheat exhibited a moderate increase in $\mathrm{C}_{\mathrm{R}}{ }^{*}$ over time, with peak values ranging from 4.4 to $7.0 \mathrm{nF}$ on DAP 53 (boot stage; $\mathrm{BBCH}$ 41-49) for the various cultivars (Figure 1b). Wheat phenology was accelerated by drought, 
especially for YQCCP, which flowered two weeks earlier. Drought provoked a sudden decrease in $C_{R}{ }^{*}$ after flowering (between DAP 65 and 88) in all treatments. As in the case of the well-watered treatment, the pea intercrop significantly reduced wheat root capacitance under drought during the greater part of the growing season (Table S1). In each treatment, drought resulted in a significant decrease in $C_{R}{ }^{*}$ from DAP 21 (leaf development stage; BBCH 14-15) onwards (Table S2).

\subsection{Minirhizotron Image Analysis}

MR image analysis demonstrated that the total RL and RSA (at 20-80 cm depths) of the well-watered crops increased rapidly until the flowering period (DAP 65-77), and subsequently declined to maturity (Figure 2a,b). In both the sole and mixed crops, the root system proved to be relatively small, medium and large, respectively for 'Mv Nádor', YQCCP and 'Mv Kolompos'. According to the paired $t$ test, maxima of RL and RSA were significantly $(p<0.01)$ higher in the sole wheat culture compared to the corresponding mixture. ARD showed similar temporal patterns, reaching a maximum between DAP 42 (late stem elongation; BBCH 34-36) and DAP 65 (early flowering), and gradually decreased thereafter (Figure 2c). Wheat genotypes 'Mv Nádor', YQCCP and 'Mv Kolompos' were characterized by thin, medium and thick root systems, respectively. In the pure wheat stands ARD significantly $(p<0.01)$ exceeded that of the intercrop counterparts.
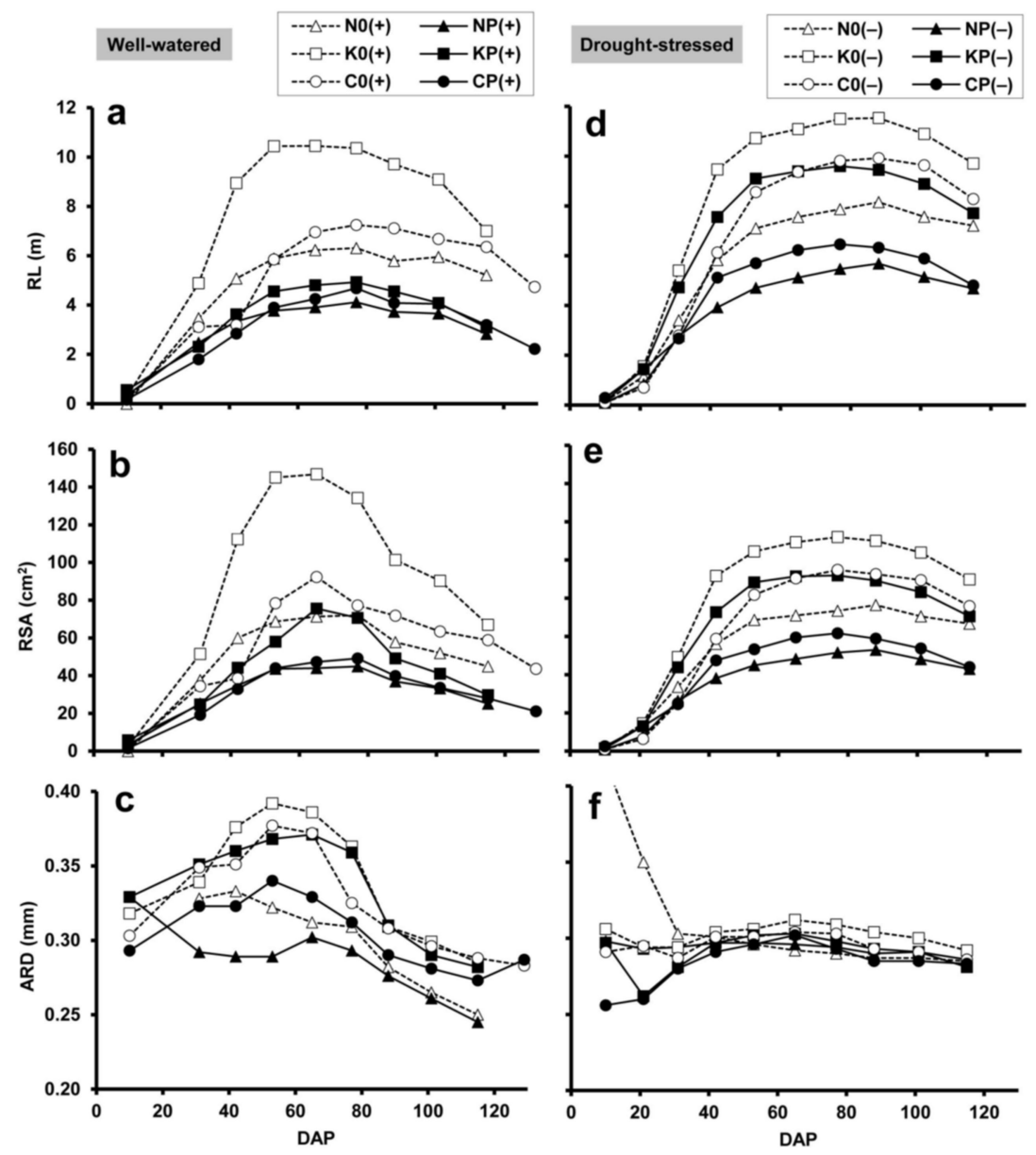

Figure 2. (a,d) Root length (RL), (b,e) root surface area (RSA) and (c,f) average root diameter (ARD), obtained by minirhizotron image analysis, in relation to plant age (DAP: days after planting) under well-watered (a-c) and drought-stressed (d-f) conditions. RL and RSA are sums from the three soil depths $(20,50$ and $80 \mathrm{~cm})$, ARD is a weighted average. For treatment codes, see Figure 1.

Under drought conditions, there was a prolonged increment in total RL and RSA until DAP 77 or 88 (milky or dough stages; BBCH 75-85), followed by a slight decline during 
maturity (Figure 2d,e). Apart from this, the differences observed in these root traits between the wheat types and between the sole and intercrops were similar to those obtained for the corresponding well-watered treatments. In most cases, water deficit increased the maximum RL and RSA, the only exception being the 'Mv Kolompos' sole crop, in which RSA was reduced by drought (however, this could be due to the relatively high basis of comparison with the well-watered plants). The paired $t$ test showed that the maximum of RL was significantly ( $p<0.01$ ) increased by drought. The peak value of ARD was significantly $(p<0.05)$ reduced both due to intercropping and due to drought, and was found to be less variable between the treatments and over time under drought conditions (Figure 2f).

The well-watered wheat cultivars showed different RL distributions in the soil profile (Figure 3a), while in dry soil all three wheats exhibited the highest RL at the $50 \mathrm{~cm}$ depth (Figure 3b). RL was usually reduced by intercropping with pea and was increased by drought at each depth.

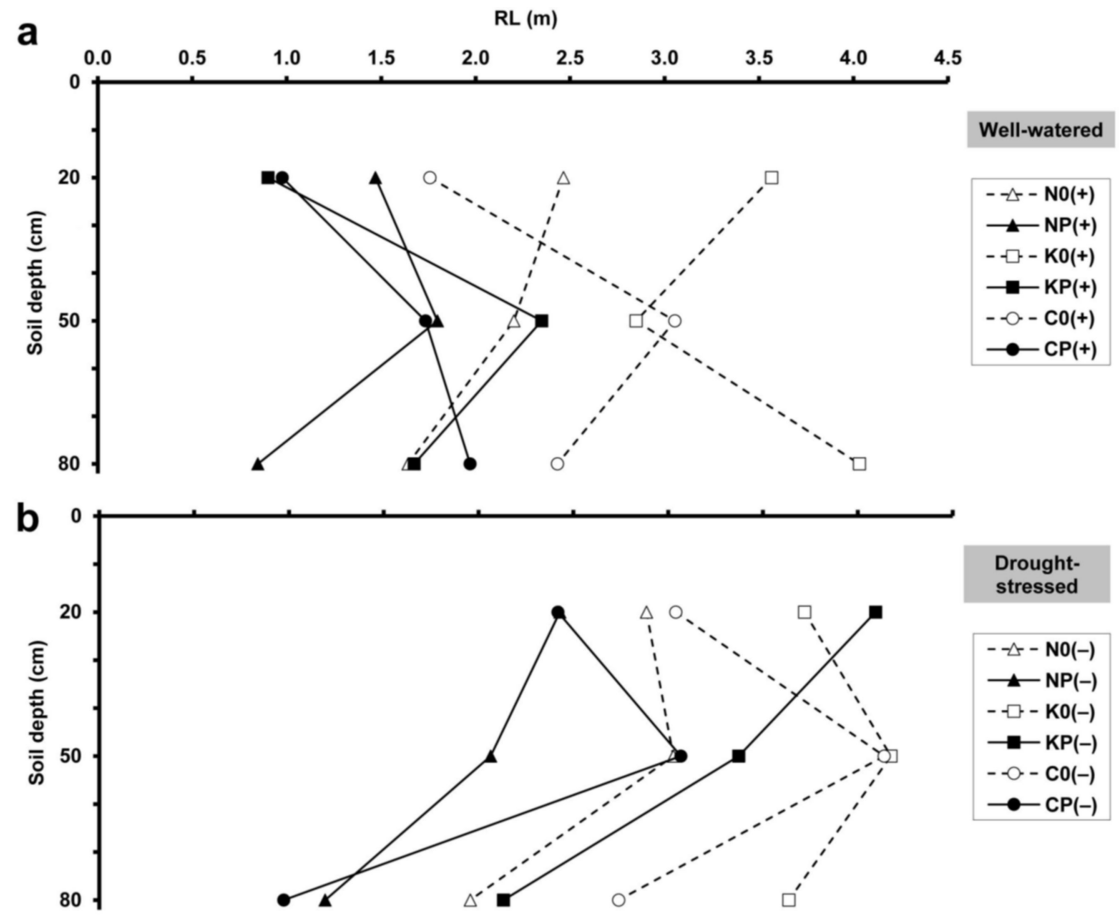

Figure 3. Maximum root length (RL) at 20,50 and $80 \mathrm{~cm}$ soil depths, obtained by minirhizotron image analysis, under (a) well-watered and (b) drought-stressed conditions. For treatment codes, see Figure 1.

\subsection{Chlorophyll Content and Yield Components}

The SPAD values measured for wheat leaves ranged from $45.2 \pm 0.5$ to $54.1 \pm 2.5$ (mean $\pm \mathrm{SD} ; n=15$; Figure $4 \mathrm{a}$ ). The presence of pea led to an overall decrease in chlorophyll content, but the change was only significant in the case of well-watered 'Mv Nádor' $(p<0.01)$, drought-stressed 'Mv Kolompos' $(p<0.05)$ and YQCCP $(p<0.001)$. Water deficit significantly $(p<0.01)$ reduced the SPAD value in each treatment. 

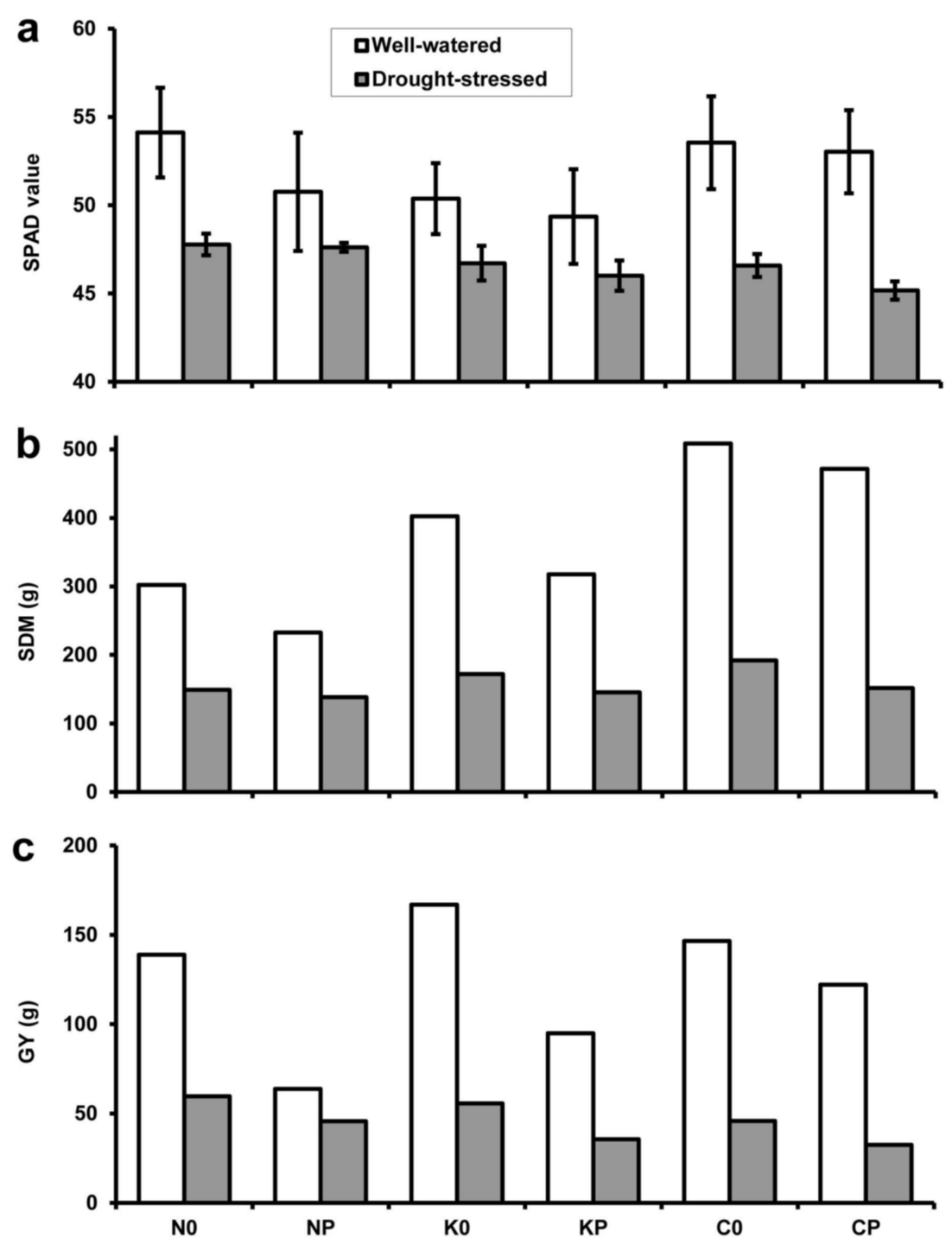

Figure 4. (a) Leaf chlorophyll content as SPAD value (mean $\pm \mathrm{SD} ; n=15)$, (b) total shoot dry mass (SDM) and (c) total grain yield (GY) under well-watered (white columns) and drought-stressed (grey columns) conditions. For treatment codes, see Figure 1.

Total wheat SDM per treatment was found to be between 138 and $508 \mathrm{~g}$ (Figure 4b). When wheat genotypes grown under the same experimental conditions were compared, SDM was always relatively low, medium and high for 'Mv Nádor', 'Mv Kolompos' and YQCCP, respectively. According to the paired $t$ test, SDM was reduced both by intercropping $(p<0.05)$ and particularly by drought stress $(p<0.01)$.

Total wheat GY varied between 36 and $167 \mathrm{~g}$ in the treatments (Figure 4c). Unlike SDM, sole-cropped 'Mv Kolompos' had the highest GY under well-watered conditions, and in the case of drought, 'Mv Nádor' exhibited the highest and YQCCP the lowest GY in both sole and mixed stands. The effect of pea intercropping and drought on GY was significant at the $p<0.05$ and $p<0.01$ levels, respectively.

\subsection{Relative Changes in Plant Parameters}

The percentage changes in maximum $C_{R}{ }^{*}, S D M, G Y$ and maximum RSA in response to pea intercropping and drought were calculated for each wheat genotype. In the case of well-watered plants, the relative decrease in $\mathrm{C}_{\mathrm{R}}{ }^{*}, \mathrm{SDM}$ and $\mathrm{GY}$ caused by pea intercropping was the lowest (5\%, 7\% and 17\%, respectively) for YQCCP, and the highest $(18 \%, 23 \%$ and 54\%) for 'Mv Nádor' (Figure 5a). Conversely, RSA showed a considerable reduction 
for 'Mv Kolompos' (49\%) and the composite population (47\%), and a relatively moderate decrease for 'Mv Nádor' (38\%).
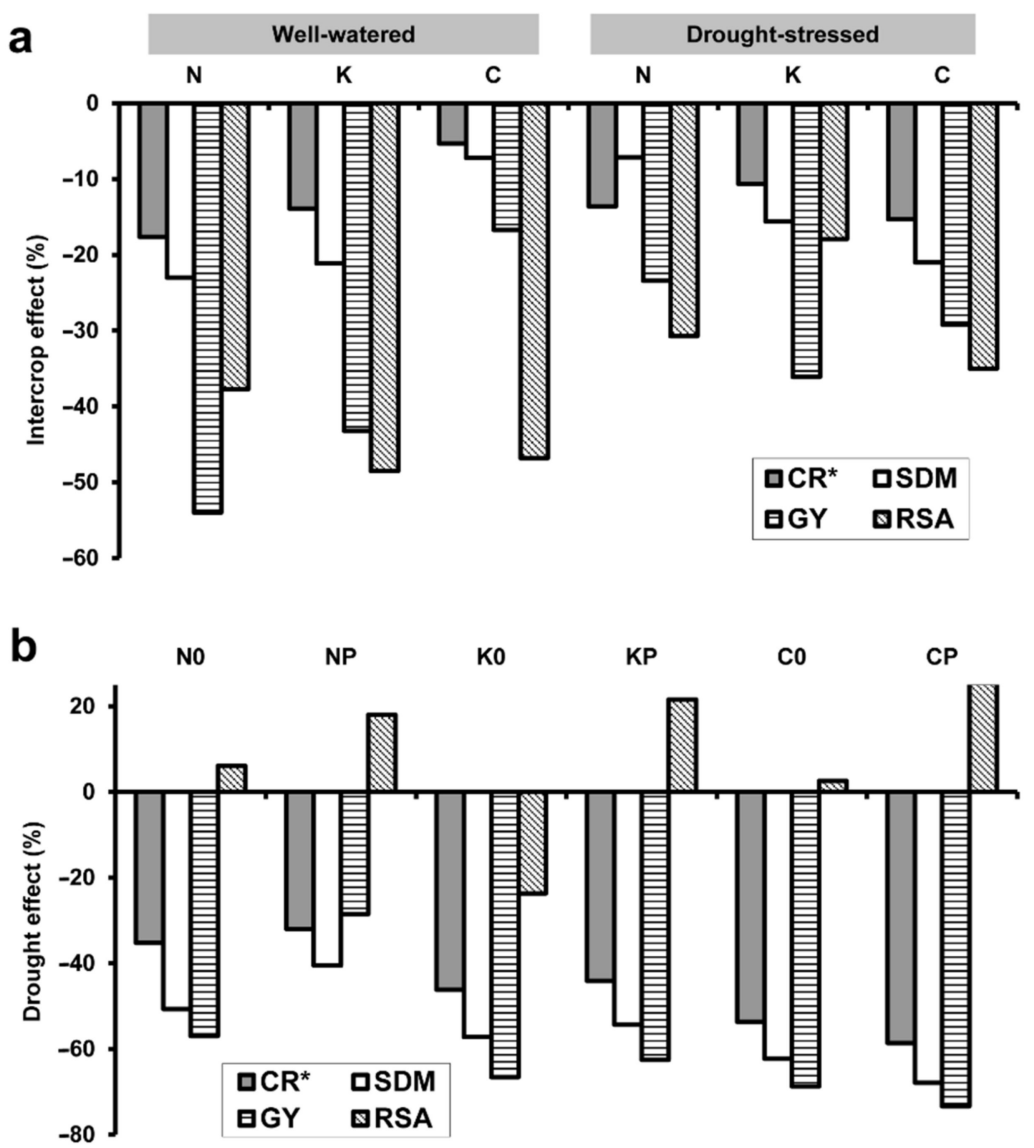

Figure 5. Percentage changes in the apparent root electrical capacitance $\left(C_{R}{ }^{*}\right)$, total shoot dry mass (SDM) and total grain yield (GY) of wheat and in the root surface area (RSA) caused by (a) pea intercropping and (b) drought stress. In the case of $C_{R}{ }^{*}$ and RSA, maximum values (detected at the wheat flowering stage) were used for calculation. For treatment codes, see Figure 1.

The presence of pea resulted in a similar decrease (11-15\%) in $C_{R}{ }^{*}$ for all the cultivars when grown under drought conditions (Figure 5a). SDM, GY and RSA dropped by 7-21\%, $23-36 \%$ and $18-35 \%$, respectively, compared to the sole crops. Pea caused the highest relative changes in $\mathrm{C}_{\mathrm{R}}{ }^{*}$, SDM and RSA in the YQCCP population, whereas the greatest loss in GY was observed for the cultivar 'Mv Kolompos'.

Drought stress reduced $C_{R}{ }^{*}$ by $32-59 \%$, SDM by $41-68 \%$ and GY by $29-73 \%$ (Figure $5 b$ ). In both sole and intercrops, the relative changes in all three parameters were comparatively low, medium and high for genotypes 'Mv Nádor', 'Mv Kolompos' and YQCCP, respectively. Except for the 'Mv Kolompos' sole crop, RSA was increased by drought in all cases (by $3-25 \%)$, but more intensely in the intercrops.

\subsection{Relationship of Electrical Capacitance to Root Surface Area}

Highly significant positive linear correlations (F: 26.9-255; $\mathrm{R}^{2}: 0.771-0.970 ; p<0.001$ ) were found between $C_{R}{ }^{*}$ and RSA for each wheat genotype and water supply (Figure 6). Analysis of covariance showed significant differences in regression slope between the genotypes under both well-watered $\left(\mathrm{F}_{2,26}=6.46 ; p<0.01\right)$ and drought-stressed conditions $\left(\mathrm{F}_{2,24}=5.08 ; p<0.05\right)$. Drought decreased the slope significantly for ' $\mathrm{Mv}$ Nádor' $\left(\mathrm{F}_{1,16}=25.3\right.$; $p<0.01)$ and $\mathrm{YQCCP}\left(\mathrm{F}_{1,18}=15.8 ; p<0.01\right)$, but non-significantly for 'Mv Kolompos' $\left(\mathrm{F}_{1,16}=3.00 ; p>0.05\right)$. 


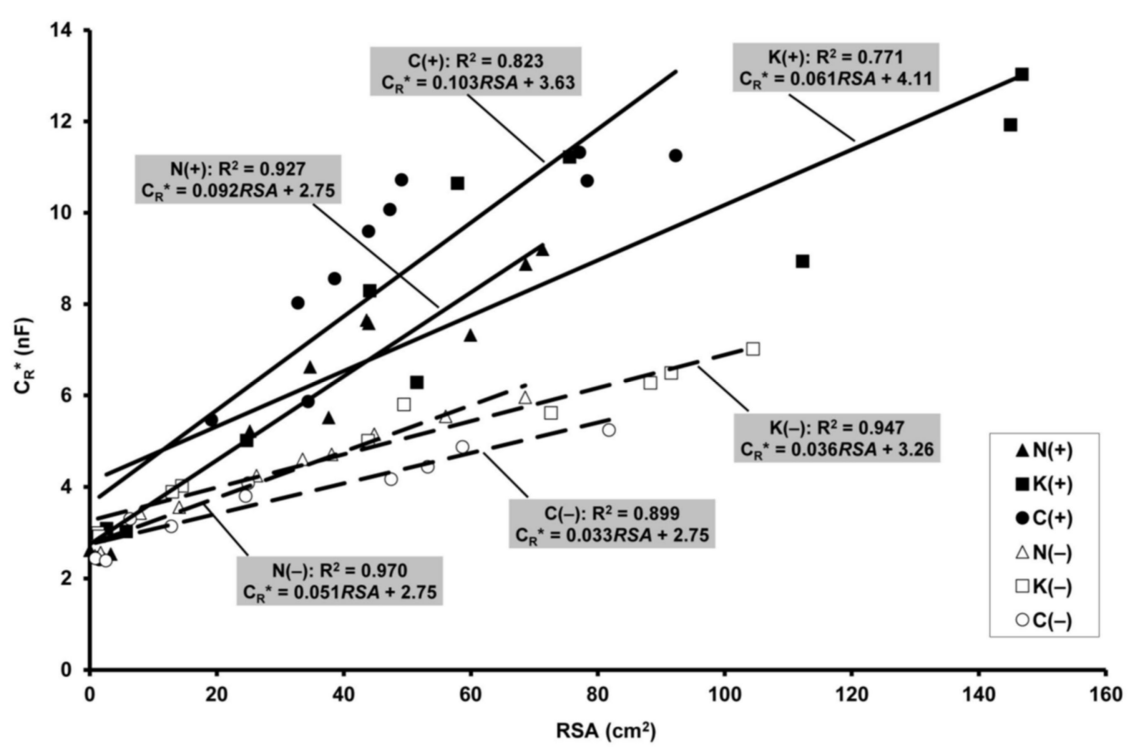

Figure 6. Linear relationships between the apparent root electrical capacitance $\left(C_{R}{ }^{*}\right)$ and root surface area (RSA) in well-watered (filled symbols and solid lines) and drought-stressed (empty symbols and dashed lines) treatments. Only data obtained up to the flowering stage of the wheat genotypes were considered, and were pooled over the two pea treatments. For treatment codes, see Figure 1.

\section{Discussion}

\subsection{Root Dynamics}

Both $C_{R}{ }^{*}$ and the MR-based root properties were found to exhibit strong patterns depending on growth status, peaking at wheat flowering for the well-watered treatments. In the case of water deficit, $C_{R}{ }^{*}$ had already started to decrease at booting, whereas the peaks of RL and RSA were postponed to the milky or dough stages. These findings are consistent with data in the literature obtained using various root methods. Annuals translocate and assimilate preferentially to the aboveground parts after flowering, and RSS increases slightly or even declines as the roots decay [33]. Previous studies reported maximum wheat root biomass, root length and root activity (water use) at about anthesis [34,35], with strong links to the concurrent peaks of green leaf area and whole-plant transpiration [36]. However, the patterns of wheat root growth may be less determinate [37], as was indicated in the present experiment by the $C_{R}{ }^{*}$ and $R L$ data obtained for the composite cross population YQCCP, which was genetically and phenologically heterogeneous [38]. Wheat ARD was reported to peak during the flowering stages, and was found to be smaller in dry soil [22].

\subsection{Effect of Drought and Intercropping}

Drought stress shortened the wheat vegetation period. Root activity $\left(C_{R}^{*}\right)$ began to decline before flowering, and showed a sudden decrease thereafter, due to enhanced lignification and accelerated root senescence [13,39]. Nevertheless, the decreasing trend in RL and RSA was observed later under drought. This was reported due to the delayed disappearance of dead roots (the visual determination of when roots reach the dead stage is subjective), especially in dry soil, where decomposition is slower [40].

The $C_{R}$ and MR methods indicated that the presence of pea had a negative effect on root growth parameters. Although intercropping systems generally give a higher total yield compared to sole crops (higher land equivalent ratio), the single component species often responds to intercropping with a reduction in biomass and grain yield [41]. The high plant density in additive intercrops often leads to strong interspecific competition between wheat and legumes below ground for soil nutrients and water (principally under drought), and above ground for light [41,42]. It was reported that pea cultivars with vigorous early development and climbing growth habit tended to overgrow the wheat (which provided mechanical support), limiting light interception for the cereal canopy [43]. This was clearly 
observed in the present study: pea overtopped the wheat, and tied up the wheat leaves with tendrils during the vegetative phase. Pea significantly reduced the SPAD chlorophyll content in well-watered 'Mv Nádor' and in drought-stressed 'Mv Kolompos' and YQCCP, in which greater aboveground biomass loss was detected under the given experimental conditions. The decreased chlorophyll content of flag leaf (the major source leaf) by drought indicated an enhanced senescence and nutrient remobilization, leading to reduced shoot and root productivity and grain yield [44,45]. 'Mv Nádor' and YQCCP were the least and the most tolerant to intercropping, respectively, under well-watered conditions, in contrast with the tolerance under drought. The reduction in cereal yield by the competitive interactions may be overcome by reducing the intercrop density.

\subsection{Benefits and Drawbacks of the Combined Approach of $C_{R}$ and $M R$}

The two different root methods provided apparently conflicting results, in that drought stress substantially decreased maximum $C_{R}{ }^{*}$ (by $32-59 \%$ ), but increased RL and RSA. Increase in root mass is a common response to limited water supply, but plant responses to drought depend greatly on timing, duration and severity [39]. In the present case, the drought was relatively moderate during the early growth stages, but became severe during flowering and grain filling, which are the most sensitive periods of wheat growth [33]. Mild drought in early growth stages have been reported not to inhibit or even to stimulate wheat root production [46], as was indicated by the present MR investigation. In accordance with the current $C_{R}{ }^{*}$ data, severe drought was observed to reduce root activity by reducing the uptake of water and promoting tissue maturation [39]. Nevertheless, another possible explanation for the decreased $C_{R}{ }^{*}$ is the smaller shoot growth and stem diameter, altering the allometry between root and shoot [8,9]. This should be taken into account as well, considering the distinct depths of $M R$ and $C_{R}$ measurements, and the uncertainties about the relative influence of deep vs. shallow roots on $C_{R}{ }^{*}[2,10]$.

An enhanced root/shoot ratio under drought is considered a typical response of plants, including wheat [46], to water deficit. In relative terms, the restricted aboveground growth (associated with reduced leaf area and total plant transpiration) decreased the water uptake of the whole root system, indicated by the decline in $C_{R}{ }^{*}$. Comparing the wheat cultivars studied, the relative change in maximum $C_{R}{ }^{*}$ induced by drought (like the effect of pea intercropping) was proportional to that in SDM and GY. 'Mv Nádor' was found to be the most tolerant to drought both in the sole crop and the intercrop, while the YQCCP was the most sensitive. Drought-stressed plants exhibited lower specific root capacitance (per unit RSA), manifested in the smaller slopes of the $C_{R}{ }^{*}-R S A$ regression lines. On the one hand, this finding may support the functional aspect of the $C_{R}$ method, pointing out that $C_{R}$ represents not only the geometrical size but also the physiological status (e.g., tissue maturity, root decay) of the root system. On the other hand, however, it demonstrates the limited comparison ability of capacitance data collected under contrasting growth conditions due to their different relationships with real RSS values. It is notable that the MR data indicated a larger RSS under drought, while the $C_{R}$ measurements did not show such a trend at all.

Many previous studies demonstrated that MR-based RL and RSA data measured at anthesis in winter wheat (mainly in deeper soil layers) were positively correlated with plant water use and grain yield [24,33,47]. However, this was not the case in the present experiment, where well-watered and severely drought-stressed plants were compared. $\mathrm{C}_{\mathrm{R}}{ }^{*}$ proved to be a more sensitive indicator of SDM and GY losses. Nevertheless, if the capacitance method is applied alone, it remains unclear to what extent the change in root size or root activity, or even only the altered root to shoot ratio (reduced stem cross-sectional area), affects $C_{R}{ }^{*}$. Transformation of measured $C_{R}$ into $C_{R}{ }^{*}$ using predetermined specific calibrations is only required to monitor root dynamics in field-grown plants under variable SWC, but is unnecessary for single measurements (which should be made around anthesis) performed under spatially homogeneous moisture conditions [16]. However, caution is required when applying the capacitance technique to compare cultivars, considering 
that, as verified in the current study, the relationship between $C_{R}{ }^{*}$ and RSS may differ markedly. Furthermore, drought-induced changes in root membrane thickness and root depth distribution (including the death of shallow fine roots and the proliferation of deep roots) can be expected to weaken the capacitance response $[10,13]$.

\subsection{Conclusions}

The current research confirmed that the $C_{R}$ and MR measurements reveal different characteristics of the root system. The parallel use of the two methods in the same plantsoil system is able to give more information about the seasonal pattern of root growth and function, and principally about the influence of experimental conditions on root traits. Root capacitance predicts the accompanying effects on aboveground biomass production and grain yield in a comparative study, whereas the MR method is more suitable for quantifying relevant RSS variables. The concurrent application of the two non-destructive techniques could provide a better understanding of how various crop genotypes respond to different cultivation practices (e.g., tillage, sowing density, fertilization) or environmental conditions (e.g., drought, elevated $\mathrm{CO}_{2}$, nutrient deficiencies). The dual methodology could be particularly beneficial under contrasting growing conditions (when root and shoot development is often asynchronous), and in plant mixtures, in which the roots of the component species are difficult to distinguish with the MR method. Nevertheless, considering the lack of treatment replications in the present model system, more extensive studies are needed for better evaluation of the benefits and drawbacks of using both techniques combined, and to fill the gap of knowledge about the disparity of changes in $C_{R}$ and MR data under stress.

\section{Materials and Methods}

\subsection{Plant Material and Growth Conditions}

The experimental design was factorial with (1) three winter wheat (Triticum aestivum L.) genotypes: the cultivars 'Mv Nádor' ("N") and 'Mv Kolompos' ("K") and the YQCCP composite cross population (" $\mathrm{C}$ "); (2) two cropping systems: wheat as sole crop (" 0 ") and a wheat-pea (Pisum satioum L., cv. Aviron) intercrop (“P”); and (3) two water treatments: wellwatered ("+") and drought-stressed ("-"). 'Mv Nádor' is an intensive, short (60-80 cm), early maturing variety, whereas 'Mv Kolompos' is a robust, less intensive, medium-tall $(85-95 \mathrm{~cm})$, medium-early cultivar. The late maturing composite cross population was created by crossing 20 parental lines in the Organic Research Centre, UK [38]. The wheat cultivars selected for the experiment were examined as a model genotypes of conventional ('Mv Nádor') and organic ('Mv Kolompos') farming systems, while the population (YQCCP) was used as a model to examine the effects of an organic heterogeneous material compared to the homogeneous varieties. The winter pea 'Aviron' is a determinate, semi-leaflet, medium-early, medium-tall $(70-85 \mathrm{~cm})$ cultivar with rapid early growth.

Six $1000 \mathrm{~L}$ cubic plastic containers were used, two (a well-watered and a droughtstressed) for each wheat genotype (Figure S1). Each container was divided into two parts (with $0.5 \mathrm{~m}^{2}$ surface area) by placing a $2 \mathrm{~cm}$ thick plastic sheet vertically, to separate the sole crop of a given genotype from the corresponding intercrop. Perpendicular to the sheet, three clear polycarbonate MR tubes $(110 \mathrm{~cm}$ long, $70 \mathrm{~mm}$ outer diameter, $4 \mathrm{~mm}$ wall thickness) with end caps were installed horizontally through each container at depths of 20,50 and $80 \mathrm{~cm}$ below the soil surface [21]. The containers were filled with topsoil $(0-30 \mathrm{~cm})$ taken from the nearby certified organic field $\left(\mathrm{N} 47^{\circ} 18^{\prime} 41^{\prime \prime}, \mathrm{E} 18^{\circ} 46^{\prime} 48^{\prime \prime}\right)$. The soil was a haplic chernozem according to the FAO-WRB [48] classification, which consisted

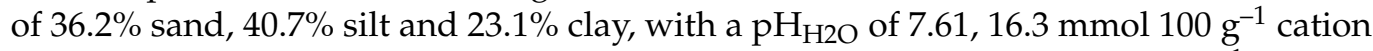
exchange capacity, $1.70 \% \mathrm{CaCO}_{3}, 3.36 \%$ humus content, $1822 / 364 / 459 \mathrm{mg} \mathrm{kg}^{-1} \mathrm{~N} / \mathrm{P} / \mathrm{K}$ content, and $1.42 \mathrm{~g} \mathrm{~cm}^{-3}$ bulk density. The SWC values at saturation, field capacity and wilting point were $47.9 \%, 28.9 \%$ and $8.7 \%$, respectively (the soil water retention curve was determined with a pressure membrane apparatus). The soil packed into the three well-watered containers was at around field capacity, but for the three drought-stressed 
containers the soil was first spread out to dry to approx. half of field capacity. The bottom of the containers was filled with fist-size stones covered with agro-textile to ensure drainage. Large clods were broken up, organic debris was removed, and the soil was compacted carefully during filling (to avoid injuring the MR tubes). SWC at 20 and $50 \mathrm{~cm}$ soil depths was recorded every $2 \mathrm{~h}$ in each experimental unit with Decagon EC-5 sensors (Decagon Devices Inc., Pullman, WA, USA) connected to Em5b dataloggers.

Wheat seeds were germinated in moistened $30 \mathrm{~mm}$ Jiffy peat pellets (Jiffy Int. AS, Kristiansand, Norway) at $22^{\circ} \mathrm{C}$ for 10 days, after which the seedlings were vernalized for 6 weeks at $+4{ }^{\circ} \mathrm{C}, 10 / 14 \mathrm{~h}$ (light/dark). Ten days before the end of vernalization, pea seeds were germinated in the same way and were planted in the containers concurrently with the wheat. Each container held a sole crop of a genotype on the one side, and the intercrop of the same genotype on the other side. Each treatment (occupied a half container) consisted of 4 rows of 38 wheat plants with $12.5 \mathrm{~cm}$ row spacing $\left(0.5 \times 1 \mathrm{~m} ; \sim 300\right.$ plants $\left.\mathrm{m}^{-2}\right)$, perpendicular to the MR tubes. Intercropping was additive, with 25 pea plants (50 plants $\mathrm{m}^{-2}$ ), five in each wheat interrow and longitudinal edge. The containers were maintained in a tempered greenhouse, initially at $15 / 10^{\circ} \mathrm{C}$ for $12 / 12 \mathrm{~h}$ (light/dark), changing gradually to $23 / 18{ }^{\circ} \mathrm{C}$ for $16 / 8 \mathrm{~h}$ during the plant growth period. The containers were arranged in two rows according to the irrigation regime, with different orders for the genotypes within a row. The orientation ensured the uniform light and ventilation conditions for each container. The SWC in the three well-watered containers was reduced to $60-70 \%$ field capacity (17-20 $v / v \%$ ), and then kept at this level by weekly irrigation. The three drought-stressed containers were given a little water $(5 \mathrm{~mm})$ at planting, after which the soil was allowed to dry to near wilting point ( $~ 9 / v \%)$, which was maintained by slight (6-10 $\mathrm{mm})$ irrigations thereafter.

In the well-watered containers, the SWC at 20 and $50 \mathrm{~cm}$ depths decreased from field capacity to 17-20 $v / v \%$ by approx. DAP (days after planting) 70 (Figure S2), and varied between 18 and $25 \mathrm{v} / \mathrm{v} \%$ in the $0-12 \mathrm{~cm}$ layer on the days when $C_{R}$ measurements were made. In the case of drought stress, the soil moisture approached the wilting point at 20 and $50 \mathrm{~cm}$ by DAP 50 (wheat booting stage) and DAP 70 (end of flowering), respectively. A range from 9 to $12 v / v \%$ SWC values were detected at $0-12 \mathrm{~cm}$ during the $C_{R}$ measurements.

\subsection{Electrical Capacitance Measurements}

Electrical measurements were performed on ten occasions throughout the growing season, between DAP 10 and 115, and an eleventh measurement was made on DAP 129 for the well-watered composite wheat owing to its longer growth period. Thirty wheat plants were randomly selected from the inner rows of each treatment. The SWC at 0-12 cm (equal to the insertion depth of the $C_{R}$ ground electrode) was recorded in the root zone of each individual plant with a pre-calibrated Campbell CS620 handheld TDR meter (Campbell Sci. Ltd., Loughborough, UK). Volumetric SWC values were converted to relative water saturation $\left(\theta_{\text {rel }}\right)$ on the basis of the predefined saturation water content. Thereafter, parallel $C_{R}$ was measured for each selected plant with an Agilent U1733C portable LCR instrument (Agilent Co. Ltd., Penang, Malaysia) at $1 \mathrm{kHz}, 1 \mathrm{~V}$ AC. The ground electrode was a stainless steel rod, $15 \mathrm{~cm}$ long and $6 \mathrm{~mm}$ in diameter (303S31; RS Pro GmbH, Gmünd, Austria), pushed vertically into the soil $5 \mathrm{~cm}$ from the stem to a depths of $12 \mathrm{~cm}$. The plant electrode was clamped to a $4 \mathrm{~mm}$ wide strip cut from a $25 \mu \mathrm{m}$ thick aluminum foil. The strip was smeared with conductivity gel, and was tied around all the basal parts of the plant $15 \mathrm{~mm}$ above the soil surface [20].

In order to take the spatial and temporal variability in SWC into account, all the $C_{R}$ data were converted into an apparent (saturation) capacitance, $C_{R}^{*}$, according to the species-specific function: $C_{R}{ }^{*}=C_{R} \cdot 5.807 \mathrm{e}^{-1.775 \theta r e l}$, using the $\theta_{\text {rel }}$ values associated with the relevant $C_{R}$. A detailed description of how the empirical equations were calculated can be found in Cseresnyés et al. [15] $C_{R}{ }^{*}$, which is equivalent in practice to the capacitance measured in a water-saturated soil $\left(\theta_{\text {rel }}=1\right)$, was considered as a proxy of the functional 
root extent (root activity). The wheat growth stage was determined on each measurement day using the $\mathrm{BBCH}$ scale [49].

\subsection{Minirhizotron Technique}

Only one MR tube per soil depth was installed in each treatment because of the relatively small container volume. MR was primarily used to track the root seasonal patterns and to evaluate the effect of intercropping and drought. On the same days when $C_{R}$ was detected, root images $(21.6 \times 19.6 \mathrm{~cm} ; 300 \mathrm{dpi})$ were recorded for each treatment and depth using a CI-600 rotary scanner (CID Bio-Science Inc., Camas, WA, USA) set to the same position in the MR tube throughout the experiment. No images were taken in the well-watered containers on DAP 21 due to a technical problem.

The images were processed with RootSnap! software (ver. 1.3.2.25), which provided root length (RL), root surface area (RSA) and average root diameter (ARD). As it was impossible to distinguish between wheat and pea roots, the total root pool of the component species was evaluated. Nevertheless, wheat roots were considered to be dominant due to the much higher planting density and the dense adventitious root system [50]. Only active roots, identified by their white to pale brown color, were considered, whereas dark brown, blurry roots were disregarded [21].

\subsection{Leaf Chlorophyll Content and Post-Harvest Measurements}

The flag leaf chlorophyll content was estimated in situ at anthesis to characterize the physiological status of wheat grown under different conditions. Fifteen plants from the central rows of each treatment were investigated using a Minolta SPAD-502 m (Konica Minolta Inc., Osaka, Japan). Three measurements taken on the same plant were averaged.

At wheat maturity (on DAP 130 and 119 for the well-watered and drought-stressed treatments, respectively), the two crops were hand harvested separately just above the soil surface. The wheat biomass was oven-dried at $70{ }^{\circ} \mathrm{C}$ to constant weight to determine the total shoot dry mass (SDM), after which the ears were threshed manually to obtain the total grain yield (GY).

\subsection{Data Analysis}

The data were analyzed using Statistica software (ver. 13; StatSoft Inc., Tulsa, OK, USA). The effect of pea intercropping and drought on the $C_{R}{ }^{*}$ and SPAD values was evaluated with an unpaired $t$ test $(p<0.05)$. Welch's correction was applied when the $F$ test indicated significant differences between the variances. A paired $t$ test was used to analyze the influence of intercropping and drought on the maxima of RL, RSA and ARD, and on SDM and GY (in this case, treatments differing only in cropping design or in water regime were paired). Simple linear regression was performed to relate $C_{R}{ }^{*}$ to RSA. In this case, only the data collected until the wheat flowering stage (when $C_{R}{ }^{*}$ and RSA peaked) were used, and pooled over cultivar sole and intercrop. The reason for this is that the correlation between capacitance and root size properties is much stronger during the most active (vegetative to flowering) plant growth stages characterized by intensive root growth, and becomes weaker during maturity stages, when root suberization, reduced activity and death can result in a sudden decrease in capacitance $[6,10]$. The regression slopes were compared with analysis of covariance.

Supplementary Materials: The following are available online at https://www.mdpi.com/article/ 10.3390/plants10101991/s1. Table S1. Effect of pea intercropping on the apparent root electrical capacitance $\left(\mathrm{CR}^{*}\right)$ of wheat at different plant ages (DAP: days after planting). Unpaired $t$ test $(n=30)$ or Welch's test [superscript $(\mathrm{W})$ in the table] was used, based on the homogeneity of variances. NS: non-significant; ${ }^{*} p<0.05 ;{ }^{* *} p<0.01$; $* * * p<0.001$. Treatment codes: N: wheat cv. Mv Nádor; K: cv. Mv Kolompos; C: YQCCP population; 0: wheat sole crop; P: wheat-pea intercrop; (+): well-watered; (-): drought-stressed. Table S2. Effect of drought stress on the apparent root electrical capacitance $\left(\mathrm{CR}^{*}\right)$ of wheat at different plant ages (DAP: days after planting). Unpaired $t$ test $(n=30)$ or Welch's test [superscript $(W)$ in the table] was used, based on the homogeneity of variances. NS: non-significant; ${ }^{*} p<0.05 ;{ }^{* *} p<0.01 ; * * * 0.001$. For treatments codes, see Table S1. Figure S1: Schematic for the 
experimental design. Treatment codes: N: wheat cv. Mv Nádor; K: cv. Mv Kolompos; C: YQCCP population; 0: wheat sole crop; P: wheat-pea intercrop; (+): well-watered; (-): drought-stressed. Figure S2: Changes in volumetric soil water content (SWC) with plant age (DAP: days after planting) in well-watered $[(+)]$ and drought-stressed $[(-)]$ treatments at different soil depths. SWC was recorded continuously at 20 and $50 \mathrm{~cm}$ depths using automatic data loggers, but only concurrently with root electrical capacitance measurements in the 0-12 cm layer with a handheld TDR meter. Data were averaged across the three wheat cultivars and two pea treatments. Horizontal dashed lines indicate water content at field capacity (FC; $0.02 \mathrm{MPa})$ and wilting point (WP; $1.5 \mathrm{MPa}$ ).

Author Contributions: I.C. conceptualized the methodological research, carried out capacitance measurements, read the relevant literature and drafted the paper. B.K. and T.T. provided expertise in minirhizotron method, analyzed root images and evaluated the data. A.F. performed the statistical analysis. R.K. and I.P. gave valuable help in plant measurements and data interpretation. M.M. participated in the setup and maintenance of the experiment. P.M. was responsible for funding acquisition and supervision of the $\mathrm{H} 2020$ project and reviewed the paper. All the authors improved the manuscript critically and approved the submission. All authors have read and agreed to the published version of the manuscript.

Funding: This research was funded by the European Union's Horizon 2020 Research and Innovation Program under grant agreement No. 727217 (ReMIX (2017-2021); www.remix-intercrops.eu, accessed on 14 September 2021) and a János Bolyai Research Scholarship from the Hungarian Academy of Sciences.

Institutional Review Board Statement: Not applicable.

Informed Consent Statement: Not applicable.

Data Availability Statement: Not applicable.

Conflicts of Interest: The authors declare no conflict of interest.

$\begin{array}{ll}\text { Abbreviations } \\ \text { AC } & \text { Alternating current } \\ \text { ARD } & \text { Average root diameter } \\ C_{R} & \text { Root electrical capacitance } \\ \text { C }_{R}^{*} & \text { Apparent (saturation) root electrical capacitance } \\ \text { DAP } & \text { Days after planting } \\ \text { GY } & \text { Grain yield } \\ \text { MR } & \text { Minirhizotron } \\ \text { RL } & \text { Root length } \\ \text { RSA } & \text { Root surface area } \\ \text { RSS } & \text { Root system size } \\ \text { SDM } & \text { Shoot dry mass } \\ \text { SWC } & \text { Soil water content }\end{array}$

\section{References}

1. Faget, M.; Nagel, K.A.; Walter, A.; Herrera, J.M.; Jahnke, S.; Schurr, U.; Temperton, V.M. Root-root interactions: Extending our perspective to be more inclusive of the range of theories in ecology and agriculture using in-vivo analyses. Ann. Bot. 2013, 112, 253-266. [CrossRef]

2. Maeght, J.-L.; Rewald, B.; Pierret, A. How to study deep roots-and why it matters. Front. Plant Sci. 2013, 4, 299. [CrossRef]

3. Postic, F.; Doussan, C. Benchmarking electrical methods for rapid estimation of root biomass. Plant Methods 2016, 12, 33. [CrossRef] [PubMed]

4. Ehosioke, S.; Nguyen, F.; Rao, S.; Kremer, T.; Placencia-Gomez, E.; Huisman, J.A.; Kemna, A.; Javaux, M.; Garré, S. Sensing the electrical properties of roots: A review. Vadose Zone J. 2020, 19, e20082. [CrossRef]

5. Chloupek, O. The relationship between electric capacitance and some other parameters of plant roots. Biol. Plant. 1972, 14, 227-230. [CrossRef]

6. Dalton, F.N. In-situ root extent measurements by electrical capacitance methods. Plant Soil 1995, 173, 157-165. [CrossRef]

7. Cabal, C.; de Deurwaerder, H.P.T.; Matesanz, S. Field methods to study the spatial root density distribution of individual plants. Plant Soil 2021, 462, 25-43. [CrossRef] 
8. Dietrich, R.C.; Bengough, A.G.; Jones, H.G.; White, P.J. A new physical interpretation of plant root capacitance. J. Exp. Bot. 2012, 63, 6149-6159. [CrossRef] [PubMed]

9. Dietrich, R.C.; Bengough, A.G.; Jones, H.G.; White, P.J. Can root electrical capacitance be used to predict root mass in soil? Ann. Bot. 2013, 112, 457-464. [CrossRef]

10. Peruzzo, L.; Chou, C.; Wu, Y.; Schmutz, M.; Mary, B.; Wagner, F.M.; Petrov, P.; Newman, G.; Blancaflor, E.B.; Liu, X.; et al. Imaging of plant current pathways for non-invasive root phenotyping using a newly developed electrical current source density approach. Plant Soil 2020, 450, 567-584. [CrossRef]

11. Ozier-Lafontaine, H.; Bajazet, T. Analysis of root growth by impedance spectroscopy (EIS). Plant Soil 2005, 277, 299-313. [CrossRef]

12. Čermák, J.; Ulrich, R.; Staněk, Z.; Koller, J.; Aubrecht, L. Electrical measurement of tree root absorbing surfaces by the earth impedance method: 2. Verification based on allometric relationships and root severing experiments. Tree Physiol. 2006, 26, 1113-1121. [CrossRef]

13. Ellis, T.; Murray, W.; Paul, K.; Kavalieris, L.; Brophy, J.; Williams, C.; Maass, M. Electrical capacitance as a rapid non-invasive indicator of root length. Tree Physiol. 2013, 33, 3-17. [CrossRef] [PubMed]

14. Cseresnyés, I.; Rajkai, K.; Takács, T. Indirect monitoring of root activity in soybean cultivars under contrasting moisture regimes by measuring electrical capacitance. Acta Physiol. Plant. 2016, 38, 121. [CrossRef]

15. Cseresnyés, I.; Szitár, K.; Rajkai, K.; Füzy, A.; Mikó, P.; Kovács, R.; Takács, T. Application of electrical capacitance method for prediction of plant root mass and activity in field-grown crops. Front. Plant Sci. 2018, 9, 93. [CrossRef] [PubMed]

16. Chloupek, O.; Dostál, V.; Středa, T.; Psota, V.; Dvořáčková, O. Drought tolerance of barley varieties in relation to their root system size. Plant Breed. 2010, 129, 630-636. [CrossRef]

17. Aulen, M.; Shipley, B. Non-destructive estimation of root mass using electrical capacitance on ten herbaceous species. Plant Soil 2012, 355, 41-49. [CrossRef]

18. Carlson, C.H.; Smart, L.B. Electrical capacitance as a predictor of root dry weight in shrub willow (Salix; Salicaceae) parents and progeny. Appl. Plant Sci. 2016, 4, 1600031. [CrossRef]

19. Wu, W.; Duncan, R.W.; Ma, B.-L. Quantification of canola root morphological traits under heat and drought stresses with electrical measurements. Plant Soil 2017, 415, 229-244. [CrossRef]

20. Svačina, P.; Středa, T.; Chloupek, O. Uncommon selection by root system size increases barley yield. Agron. Sustain. Dev. 2014, 34, 545-551. [CrossRef]

21. Vamerali, T.; Bandiera, M.; Mosca, G. Minirhizotrons in modern root studies. In Measuring Roots; Mancuso, S., Ed.; Springer: Berlin, Germany, 2012; pp. 341-361. [CrossRef]

22. Muñoz-Romero, V.; Benítez-Vega, J.; López-Bellido, L.; López-Bellido, R.J. Monitoring wheat root development in a rainfed vertisol: Tillage effect. Eur. J. Agron. 2010, 33, 182-187. [CrossRef]

23. Milchunas, D.G. Estimating root production: Comparison of 11 methods in shortgrass steppe and review of biases. Ecosystems 2009, 12, 1381-1402. [CrossRef]

24. Postic, F.; Beauchêne, K.; Gouache, D.; Doussan, C. Scanner-based minirhizotrons help to highlight relations between deep roots and yield in various wheat cultivars under combined water and nitrogen deficit conditions. Agronomy 2019, 9, 297. [CrossRef]

25. Bedoussac, L.; Justes, E. The efficiency of a durum wheat-winter pea intercrop to improve yield and wheat grain protein concentration depends on N availability during early growth. Plant Soil 2010, 330, 19-35. [CrossRef]

26. Pankou, C.; Lithourgidis, A.; Dordas, C. Effect of irrigation on intercropping systems of wheat (Triticum aestivum L.) with pea (Pisum sativum L.). Agronomy 2021, 11, 283. [CrossRef]

27. Knörzer, H.; Graeff-Hönninger, S.; Guo, B.; Wang, P.; Claupein, W. The rediscovery of intercropping in China: A traditional cropping system for future Chinese agriculture. In Climate Change, Intercropping, Pest Control and Beneficial Microorganisms. Sustainable Agriculture Reviews 2; Lichtfouse, E., Ed.; Springer: Dordrecht, The Netherlands, 2009; pp. 13-44. [CrossRef]

28. Aziz, M.; Mahmood, A.; Asif, M.; Ali, A. Wheat-based intercropping: A review. J. Anim. Plant Sci. 2015, 25, 896-907.

29. Klimek-Kopyra, A.; Zając, T.; Oleksy, A.; Kulig, B. Biological and production responses of intercropped plants of pea, spring wheat, and linseed. Acta Agrobot. 2018, 71, 1737. [CrossRef]

30. Ghaley, B.B.; Hauggaard-Nielsen, H.; Høgh-Jensen, H.; Jensen, E.S. Intercropping of wheat and pea as influenced by nitrogen fertilization. Nutr. Cycl. Agroecosyst. 2005, 73, 201-212. [CrossRef]

31. Amossé, C.; Jeuffroy, M.-H.; David, C. Relay intercropping of legume cover crops in organic winter wheat: Effects on performance and resource availability. Field Crop. Res. 2013, 145, 78-87. [CrossRef]

32. Naudin, C.; Corre-Hellou, G.; Pineau, S.; Crozat, Y.; Jeuffroy, M.-H. The effect of various dynamics of N availability on winter pea-wheat intercrops: Crop growth, $\mathrm{N}$ partitioning and symbiotic $\mathrm{N}_{2}$ fixation. Field Crop. Res. 2010, 119, 2-11. [CrossRef]

33. Fageria, N.K. The Role of Plant Roots in Crop Production; CRC Press: Boca Raton, FL, USA, 2013.

34. Hodgkinson, L.; Dodd, I.C.; Binley, A.; Ashton, R.W.; White, R.P.; Watts, C.W.; Whalley, W.R. Root growth in field-grown winter wheat: Some effects of soil conditions, season and genotype. Eur. J. Agron. 2017, 91, 74-83. [CrossRef]

35. Jha, S.K.; Gao, Y.; Liu, H.; Huang, Z.; Wang, G.; Liang, Y.; Duan, A. Root development and water uptake in winter wheat under different irrigation methods and scheduling for North China. Agr. Water Manage. 2017, 182, 139-150. [CrossRef]

36. Yang, B.; Wang, P.; You, D.; Liu, W. Coupling evapotranspiration partitioning with root water uptake to identify the water consumption characteristics of winter wheat: A case study in the North China Plain. Agr. For. Meteorol. 2018, 259, 296-304. [CrossRef] 
37. Herrera, J.M.; Stamp, P.; Liedgens, M. Interannual variability in root growth of spring wheat (Triticum aestivum L.) at low and high nitrogen supply. Eur. J. Agron. 2007, 26, 317-326. [CrossRef]

38. Döring, T.; Wolfe, M.; Jones, H.; Pearce, H.; Zhan, J. Breeding for resilience in wheat-Nature's choice. In Eucarpia 2 nd Conference of the Organic and Low-Input Agriculture Section; Goldringer, I., Dawson, J.C., Rey, F., Vettoretti, A., Chable, V., Lammerts van Bueren, E., Finckh, M., Barot, S., Eds.; INRA: Paris, France, 2010; pp. 47-50.

39. De Micco, V.; Aronne, G. Morpho-anatomical traits for plant adaptation to drought. In Plant Responses to Drought Stress; Aroca, R., Ed.; Springer: Heidelberg, Germany, 2012; pp. 37-62. [CrossRef]

40. Hooker, J.E.; Hendrick, R.; Atkinson, D. The measurement and analysis of fine root longevity. In Root Methods: A Handbook; Smit, A.L., Bengough, A.G., Engels, C., van Noordwijk, M., Pellerin, S., van de Geijn, S.C., Eds.; Springer: Berlin, Germany, 2000; pp. 273-304. [CrossRef]

41. Monti, M.; Pellicanò, A.; Santonoceto, C.; Preiti, G.; Pristeri, A. Yield components and nitrogen use in cereal-pea intercrops in Mediterranean environment. Field Crop. Res. 2016, 196, 379-388. [CrossRef]

42. Mariotti, M.; Masoni, A.; Ercoli, L.; Arduini, I. Above- and below-ground competition between barley, wheat, lupin and vetch in a cereal and legume intercropping system. Grass Forage Sci. 2009, 64, 401-412. [CrossRef]

43. Pelzer, E.; Bazot, M.; Makowski, D.; Corre-Hellou, G.; Naudin, C.; Al Rifaï, M.; Baranger, E.; Bedoussac, L.; Biarnès, V.; Boucheny, P.; et al. Pea-wheat intercrops in low-input conditions combine high economic performances and low environmental impacts. Eur. J. Agron. 2012, 40, 39-53. [CrossRef]

44. Gregersen, P.L.; Culetic, A.; Boschian, L.; Krupinska, K. Plant senescence and crop productivity. Plant Mol. Biol. 2013, 82, 603-622. [CrossRef]

45. Monostori, I.; Árendás, T.; Hoffman, B.; Galiba, G.; Gierczik, K.; Szira, F.; Vágújfalvi, A. Relationship between SPAD value and grain yield can be affected by cultivar, environment and soil nitrogen content in wheat. Euphytica 2016, 211, 103-112. [CrossRef]

46. Asseng, S.; Ritchie, J.T.; Smucker, A.J.M.; Robertson, M.J. Root growth and water uptake during water deficit and recovering in wheat. Plant Soil 1998, 201, 265-273. [CrossRef]

47. Wang, C.; Liu, W.; Li, Q.; Ma, D.; Lu, H.; Feng, W.; Xie, Y.; Zhu, Y.; Gou, T. Effects of different irrigation and nitrogen regimes on root growth and its correlation with above-ground plant parts in high-yielding wheat under field conditions. Field Crop. Res. 2014, 165, 138-149. [CrossRef]

48. IUSS Working Group. World Reference Base (WRB) for Soil Resources 2014, Update 2015. International Soil Classification System for Naming Soils and Creating Legends for Soil Maps; World Soil Resources Reports 106; FAO: Rome, Italy, 2015.

49. Meier, U. (Ed.) Growth Stages of Mono- and Dicotyledonous Plants. BBCH Monograph, 2nd ed.; Federal Biological Research Centre for Agriculture and Forestry: Berlin, Germany, 2001.

50. Liu, L.; Gan, Y.; Bueckert, R.; van Rees, K. Rooting systems of oilseed and pulse crops I: Temporal growth patterns across the plant developmental periods. Field Crop. Res. 2011, 122, 256-263. [CrossRef] 